\title{
Different Adaptive Responses to Hypoxia in Normal and Multiple Myeloma Endothelial Cells
}

\author{
Irene Filippi ${ }^{a, b}$ Ilaria Saltarella ${ }^{c}$ Carlo Aldinuccia Fabio Carraro ${ }^{a, b}$ Roberto Ria \\ Angelo Vaccac Antonella Naldinia \\ ${ }^{a}$ Cellular and Molecular Physiology Unit, Department of Molecular and Developmental Medicine, \\ University of Siena, Siena, ' ${ }^{2}$ stituto Toscano Tumori, Firenze, 'Department of Biomedical Sciences and \\ Human Oncology, Section of Internal Medicine and Clinical Oncology, University of Bari, Bari, Italy
}

\section{Key Words}

Hypoxia • Cell survival $•$ Endothelial Cells $・$ Multiple Myeloma $•$ BNIP3

\begin{abstract}
Background/Aims: Hypoxia is a powerful stimulator of angiogenesis under physiological as well as pathological conditions. Normal endothelial cells (EC), such as human umbilical vein EC (HUVEC), are relatively affected by hypoxic insult in terms of cell survival. In contrast, EC from tumors are particularly resistant to hypoxia-induced cell death. Previous reports have shown that $\mathrm{EC}$ in bone marrow from multiple myeloma (MM) patients had a hypoxic phenotype, even under normoxic conditions. The aim of this study was to evaluate whether HUVEC and MMEC adapt differently to hypoxia. Methods: Cell proliferation was assessed by the CyQUANT assay. Cdc25A, p21, Bax, Bcl-xl, BNIP3, glucose transporter (GLUT)-1, monocarboxylate transporter (MCT)-4 and carbonic anhydrase (CA)IX mRNA expression was determined by qRT-PCR. HIF-1 $\alpha$, BNIP3, Beclin-1, LC3B, livin, Bax, Bcl-xl, p21, p62 and $\beta$-actin protein expression was analyzed by western blot. Apoptosis was determined by TUNEL assay. Silencing of BNIP3 was achieved by stealth RNA system technology. Results: While HUVEC survival was reduced after prolonged hypoxic exposure, MMEC were completely unaffected. This difference was also significant in terms of livin, cdc25A and p21 expression. Hypoxia induced apoptosis and inhibited autophagy in HUVEC, but not in MMEC, where hypoxic treatment resulted in a more sustained adaptive response. In fact, MMEC showed a more significant increase in the expression of genes regulated transcriptionally by hypoxia-inducible factor (HIF)- $1 \alpha$. Interestingly, they showed higher expression of BNIP3 than did HUVEC, indicating a more pronounced autophagic (and pro-survival) phenotype. The potential role of BNIP3 in EC survival was confirmed by BNIP3 siRNA experiments in HUVEC, where BNIP3 inhibition resulted in reduced cell survival and increased apoptosis. Conclusion: These findings provide further information on how hypoxia may affect EC survival and could be important for a better understanding of EC physiology under normal and pathological conditions, such as in multiple myeloma.
\end{abstract}




\section{Cellular Physiology Cell Physiol Biochem 2018;46:203-212 and Biochemistry Published onIme:IVarch 26, 2018 \begin{tabular}{l|l} 
DOI: 10.1159/000488423 & $\begin{array}{l}\text { (c) } 2018 \text { The Author(s). Published by S. Karger AG, Basel } \\
\text { www.karger.com/cpb }\end{array}$
\end{tabular}}

Filippi et al.: Endothelial Cell Survival Under Hypoxia

\section{Introduction}

Hypoxia is a common feature in various physiological and pathological conditions [1]. Different types of cells may adapt differently to hypoxia by modulating gene expression through the transcription factor hypoxia-inducible factor (HIF)-1 to overcome oxygen shortage [2]. HIF- 1 is an $\alpha \beta$-heterodimer and HIF- $\alpha$ and HIF- $\beta$ subunits exist as a series of isoforms encoded by distinct genetic loci [3]. HIF-1 $\beta$ can dimerize with different basic helix-loop-helix-PAS proteins and is constitutive, while HIF- $\alpha$ subunits are induced by hypoxia. Of the three HIF- $\alpha$ isoforms, HIF- $1 \alpha$ is the primary source of hypoxic transcriptional response $[4,5]$, which involves interacting with hypoxia response elements (HREs) to induce transcriptional activity [6].

The role of the HIF pathway in cell death is controversial; HIF-1 can induce apoptosis and autophagy, prevent cell death, or even stimulate cell proliferation. Indeed, HIF-1 $\alpha$ activates transcription of genes encoding Bcl-2/adenovirus E1B 19-kDa interacting protein 3 (BNIP3), which triggers selective autophagy [7]. Interdependence between autophagy and apoptosis seems to depend on cell type and the cellular environment. However, it has been clearly demonstrated that autophagy is a basic mechanism for maintaining cellular homeostasis, as well as a survival strategy $[8,9]$.

With regard to cell death, endothelial cells (EC) are less susceptible than other cell types to hypoxic stress [10]. They tend to adapt better to hypoxia in terms of cell survival [11]. Furthermore, EC of tumor vessels differ greatly from those of quiescent healthy vessels [12]: they proliferate rapidly, in keeping with the enhanced angiogenesis associated with tumor progression (growth, invasion and metastasis). Their survival not only depends on the growth factors (and their receptors) in the tumor microenvironment, but also on hypoxia [13].

Previous reports have shown that bone marrow angiogenesis is a constant hallmark of progression of multiple myeloma (MM) [14]. Indeed, MM endothelial cells (MMEC) play a crucial role in MM progression and HIF-1 $\alpha$ protein is reported to be expressed constitutively and activated in MMEC in a well-defined proportion of patients experiencing relapse or refractory to treatment. More importantly, patients with MMEC expressing the HIF-1 $\alpha$ protein have shorter overall survival [15].

Although the pro-angiogenic role of HIF- $1 \alpha$ has already been established in MM [15, 16], to our knowledge no studies have documented MMEC adaptive response to hypoxia in terms of survival, apoptosis and/or autophagy. We therefore decided to investigate and compare the effects of hypoxia on bone marrow EC of active multiple myeloma patients and on healthy quiescent EC, namely human umbilical vein EC (HUVEC).

\section{Materials and Methods}

\section{Cell culture and hypoxic treatment}

HUVEC and appropriate growth medium were purchased from Lonza (Walkersville, MD, USA) and cultured with $10 \%$ FBS, as indicated by the manufacturer. Bone marrow primary multiple myeloma endothelial cells (MMEC) were obtained as previously described [14] and cultured in Dulbecco's Modified Eagle's Medium (DMEM) (Euroclone, Devon, UK) supplemented with 20\% FBS. The experiments, conducted under aerobic conditions, were performed using an incubator (VWR International PBI, Milano, Italy) set at $5 \% \mathrm{CO}_{2}, 20 \% \mathrm{O}_{2}$ (atmospheric oxygen $\approx 140 \mathrm{mmHg}$ ) and $37^{\circ} \mathrm{C}$ in a humidified environment. The experiments under hypoxic conditions were performed using a workstation InVivo 400 (Ruskinn, Pencoed, UK) which provides a stable customized humidified environment through electronic control of $\mathrm{CO}_{2}(5 \%), \mathrm{O}_{2}$ and temperature $\left(37^{\circ} \mathrm{C}\right)$. In our experiments, $\mathrm{O}_{2}$ was set and maintained constantly at $2 \%(\approx 14 \mathrm{mmHg}) \mathrm{by}$ injecting $\mathrm{N}_{2}$ automatically into the chamber, as previously described [17]. Cells were plated and allowed to adhere overnight. The next morning they were incubated in normoxia or hypoxia for the indicated times. At the end of the experiments, the cells were analyzed as follows.

\section{KARGER}




\section{Cellular Physiology \begin{tabular}{l|l} 
DOI: 10.1159/000488423 & $\begin{array}{l}\text { (c) 2018 The Author(s). Published by S. Karger AG, Basel } \\
\text { www.karger.com/cpb }\end{array}$
\end{tabular}}

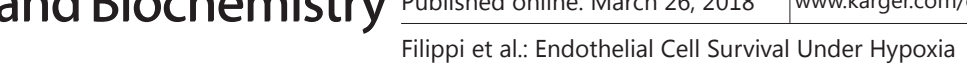

Cell proliferation assay

Cell proliferation was assessed with the CyQUANT Kit (Molecular Probe, Eugene, OR, USA), according to the manufacturer's instructions, as previously described [18]. Cells $\left(2 \times 10^{4}\right.$ cells $\left./ \mathrm{ml}\right)$ were exposed to normoxia or hypoxia for 8-24-48 h. Fluorescence was measured using a microplate reader (FluostarOptima, BMG LABTECH, Durham, NC, USA).

RNA preparation and real-time $P C R$

Cdc25A, p21(p21/WAF1), Bax, Bcl-xl, BNIP3, glucose transporter (GLUT)-1, monocarboxylate transporter (MCT)-4 and carbonic anhydrase (CA)IX mRNA expression was determined by real-time PCR using an $\mathrm{iQ}^{\mathrm{TM}} 5$ Multicolor Real-Time PCR Detection System (Bio-Rad Laboratories, Hercules, CA, USA) as previously described [17]. Briefly, total RNA was extracted from normoxic or hypoxic cells using the TRI Reagent ${ }^{\circledR}$ (Ambion, Austin, TX, USA). First-strand cDNA was synthesized using an iScript ${ }^{\mathrm{TM}}$ cDNA Synthesis Kit (Bio-Rad Laboratories). qRT-PCR was performed using iTaq ${ }^{\mathrm{TM} S Y B R}$ Green Supermix (Bio-Rad Laboratories) and the specific primers were designed by the Primer-BLAST program (available at https://blast.ncbi.nlm. nih.gov). Thermocycler conditions included an initial hold at $95^{\circ} \mathrm{C}$ for $30 \mathrm{sec}$, followed by a two-step PCR program: $95^{\circ} \mathrm{C}$ for $10 \mathrm{sec}$ and $60^{\circ} \mathrm{C}$ for $30 \mathrm{sec}$ for 49 cycles. CAIX mRNA expression was determined by TaqMan-Based Multiplex real-time PCR. p21 (p21/WAF1), Bax, Bcl-xl, BNIP3, GLUT-1 and MCT-4 primers were purchased from Invitrogen (Paysley, UK), while Cdc25A and CAIX primers and TaqMan probes were obtained from Eurofins Genomics (Ebersberg, Germany). Data were analyzed quantitatively with $\mathrm{iQ}^{\mathrm{TM}} 5$ Optical System Software (Bio-Rad Laboratories). Relative quantification was done using the $2^{-\Delta \Delta c T}$ method [19] and $\beta$-actin was used as housekeeping control. The specificity of PCR amplification of each primer pair was confirmed analyzing PCR products by agarose gel electrophoresis and melting curve analysis.

\section{Western blot analysis}

For western blot analysis, cells were promptly processed to avoid culture reoxygenation, appropriately lysed and analyzed using antibodies against HIF- $1 \alpha$ (BD Biosciences, San Jose, CA), BNIP3 (Thermo Scientific, Rockford, IL, USA), Beclin-1, LC3B, p62, Bax, Bcl-xl and $\beta$-actin (Cell Signaling, Danvers, MA, USA) and p21 (p21/WAF1; Oncogene Research Products, San Diego, CA). Chemiluminescence was detected and quantified using a ChemiDoc XRS apparatus and Quantity One software (Bio-Rad Laboratories) as previously described [17].

\section{Human apoptosis array}

Analysis of livin protein expression was performed with a Human Apoptosis Array kit (R\&D Systems, Minneapolis, MN, USA). Both normoxic and hypoxic cells were lysed in the appropriate buffer at $2-8^{\circ} \mathrm{C}$ for $30 \mathrm{~min}$ and processed according to the manufacturer's instructions. Chemiluminescence was detected by ChemiDoc XRS/Quantity One software (Bio-Rad Laboratories) and quantitative evaluation was based on pixel densities, which were calculated and normalized to reference spots, as indicated by the manufacturer.

\section{TUNEL Assay}

Apoptosis was determined on cells exposed to normoxia or hypoxia for $48 \mathrm{~h}$. A terminal deoxynucleotidyl transferase dUTP nick-end labeling (TUNEL) assay was conducted using an HT Titer-TACS ${ }^{\text {TM }}$ assay kit (Trevigen, Gaithersburg, MD, USA) according to the manufacturer's protocol. TUNEL-positive cells were measured at absorbance $450 \mathrm{~nm}$ using a Multiskan EX 96-well plate reader (Thermo Scientific, Rockford, IL, USA) after addition of $0.2 \mathrm{~N} \mathrm{HCl}$. As positive control, cells were treated with TACS-nuclease, supplied with the assay kit, for $1 \mathrm{~h}$ at $37^{\circ} \mathrm{C}$ before hydrogen peroxide treatment.

\section{BNIP3 SIRNA}

Silencing of BNIP3 was achieved by stealth RNA system technology (Invitrogen). The siRNA target sequences are Exon 2 (NM_004052) of human BNIP3 mRNA; negative controls were designed with the same CG ratio without any known human genome target. HUVEC were transfected in suspension using $\mathrm{Neon}^{\mathrm{TM}}$ Transfection System (Invitrogen) according to the manufacturer's instructions and incubated for $24 \mathrm{~h}$ with stealth RNA at a concentration of $50 \mathrm{nM}$. Following transfection, cells were exposed to normoxia or hypoxia for $48 \mathrm{~h}$. Real-time PCR, western blot analysis, cell proliferation and apoptosis were conducted as described above.

\section{KARGER}




\section{Cellular Physiology Cell Physiol Biochem 2018;46:203-212 \begin{tabular}{ll|l} 
and Biochemistry Published onIIne: IVIarch 26, 2018 & $\begin{array}{l}\text { (C) } 2018 \text { The Author(s). Published by S. Karger AG, Basel } \\
\text { www.karger.com/cpb }\end{array}$
\end{tabular}

Statistical analysis

Statistical significance between means was determined using Student's t test. A value of $\mathrm{p}<0.05$ was considered statistically significant.

\section{Results}

Hypoxia affects HUVEC and MMEC proliferation differently

Although HUVEC proliferation was relatively affected by hypoxia, MMEC were completely resistant. The HUVEC viability assay revealed an apparent reduction in cell proliferation after $24 \mathrm{~h}$ of continuous exposure to an oxygen partial pressure of $14 \mathrm{mmHg}$ (Fig. 1a). The reduction became statistically significant after $48 \mathrm{~h}$ of hypoxic treatment. In contrast, MMEC proliferation was not affected by $24 \mathrm{~h}$ of hypoxia, or even $48 \mathrm{~h}$ of continuous exposure. HUVEC and MMEC proliferation patterns under hypoxia were evaluated by several techniques. The human apoptosis array kit revealed significant enhancement of expression of the protein livin (an apoptosis inhibitor) in MMEC exposed to hypoxia for 48 h, in contrast with HUVEC (Fig. 1b). We also determined the expression of cdc $25 \mathrm{~A}$, a member of the cdc25 family of phosphatases, which is required for progression from G1 to the $S$ phase of the cell cycle. As shown in Fig. 1c, cdc25A mRNA expression was significantly enhanced in hypoxic MMEC, and significantly reduced in HUVEC. In contrast, mRNA and protein expression of the cyclin-dependent kinase inhibitor 1 , p21, was significantly enhanced in HUVEC and reduced in MMEC, confirming resistance of MMEC to hypoxic insult (Fig. 1d).

MMEC are more resistant to hypoxia-induced cell death than HUVEC

Since HUVEC and MMEC viabilities were differently affected by hypoxia, we decided to evaluate the mechanism involved. Cell death was analyzed by different approaches to determine whether it was related to apoptosis.

To detect cell apoptosis, DNA fragmentation was evaluated by

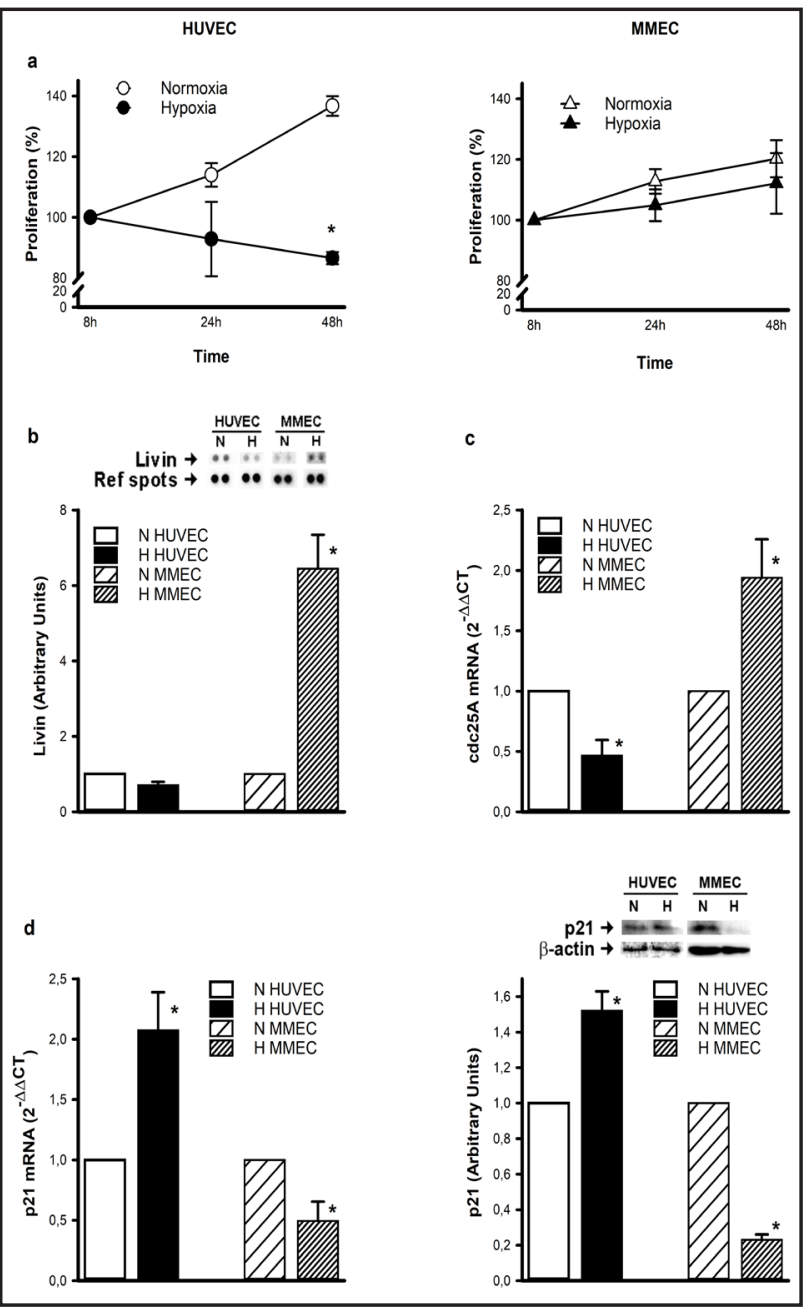

Fig. 1. HUVEC and MMEC proliferation under hypoxia. (a) Cells were exposed to hypoxia for 8-24-48 h and cell proliferation was expressed as a percentage with respect to controls at $8 \mathrm{~h}$. (b) Livin protein expression was determined by a human apoptosis array kit after 48 h of hypoxia. (c) cdc25A mRNA expression was determined by real-time PCR after 48 $\mathrm{h}$ of hypoxic treatment. (d) p21 mRNA and protein expression were assessed at $48 \mathrm{~h}$ by real-time PCR and western blot analysis using $\beta$-actin as protein loading control. Representative blots from three independent experiments for livin and p21 are shown. Densitometric quantification of protein expression was achieved by chemiluminescence and is expressed in relation to normoxic controls. Data are means \pm SEM of three separate experiments. ${ }^{*} \mathrm{p}<0.05$, hypoxia versus normoxia. 
TUNEL assay on HUVEC and MMEC exposed to hypoxia. In HUVEC, 48 $\mathrm{h}$ exposure induced a significant increase in the percentage of apoptotic cells, whereas MMEC were unaffected (Fig. 2a). Since the ratio of Bax to Bcl-xl expression is an index of apoptosis, we calculated it at mRNA and protein levels by realtime PCR and western blot analysis. With the TUNEL assay results, 48 $h$ exposure to hypoxia enhanced the Bax/Bcl-xl ratio at mRNA and protein levels in HUVEC, whereas it was significantly reduced in MMEC (Fig. 2b). This indicates that HUVEC are more prone to apoptosis than MMEC under hypoxia. Finally, we decided to investigate whether hypoxia affects expression of proautophagic markers, such as Beclin-1 and LC3B-I and -II, in different ways (Fig. 2c). Interestingly, $48 \mathrm{~h}$ exposure to hypoxia resulted in a significant reduction in Beclin-1 expression in HUVEC. We also observed a similar reduction in the LC3B-II/ LC3B-I ratio, indicating an impaired autophagic process. In contrast, hypoxia did not affect expression of these autophagic markers in MMEC. For a better characterization of autophagy, we also evaluated expression of p62, a protein whose degradation is normally associated with autophagic flux [20]. In our experiments, p62 expression was only significantly reduced in hypoxic MMEC and not in HUVEC (Fig. 2d). The overall results indicate that HUVEC are more prone to apoptosis and less predisposed to autophagy than MMEC, supporting the hypothesis that MMEC are more resistant to hypoxia-induced cell death than HUVEC.

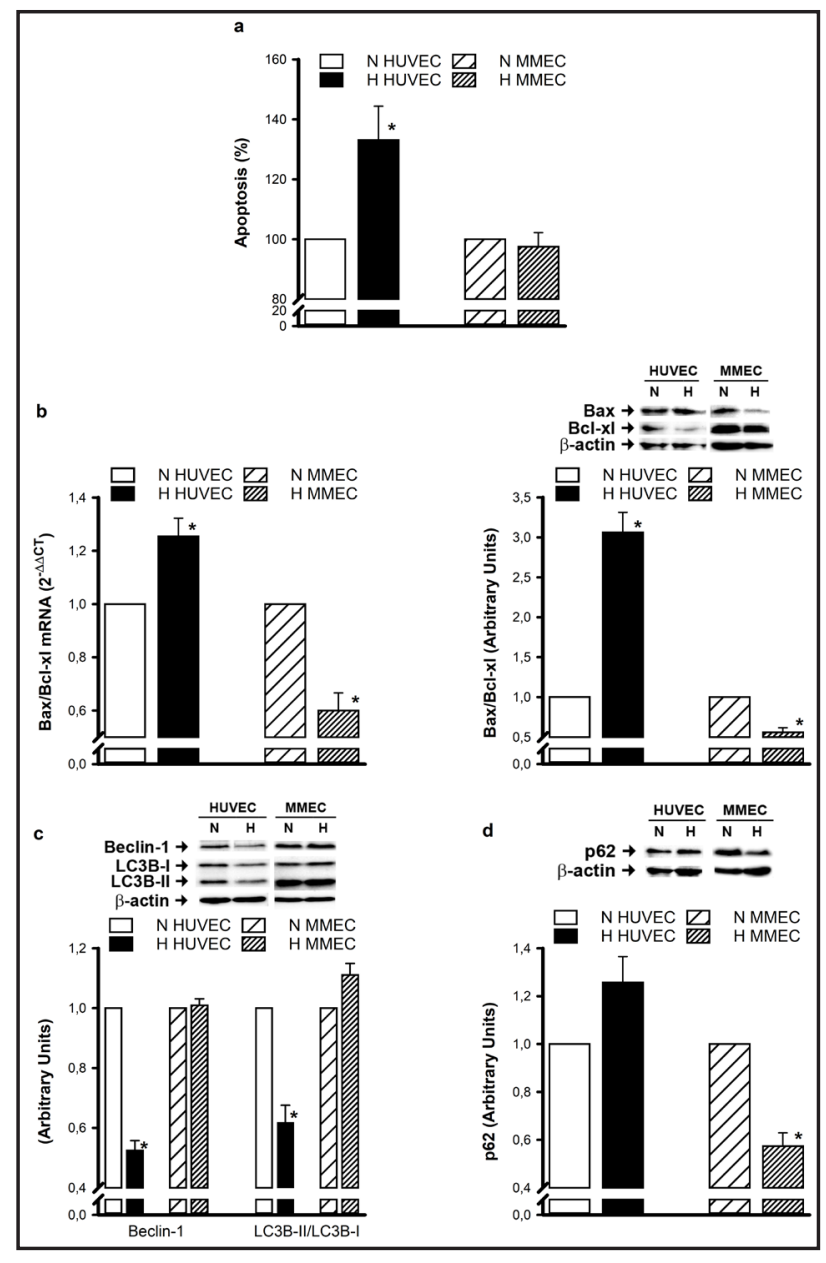

Fig. 2. Hypoxia-induced cell death in MMEC and HUVEC. (a) Apoptosis was determined by TUNEL assay on cells exposed to hypoxia for $48 \mathrm{~h}$. Data are expressed as percentages with respect to normoxic controls. (b) Bax and Bcl-xl mRNA and protein expression, assessed by real-time PCR and western blot analysis, are reported as Bax/Bcl-xl ratio. (c) Protein expression of Beclin-1, LC3B-I and LC3B-II, (d) p62 was evaluated by western blot analysis using $\beta$-actin as protein loading control. A representative blot from three independent experiments is shown. Densitometric quantification of protein expression was achieved by chemiluminescence and is expressed in relation to normoxic controls for Bax/Bcl-xl, Beclin and LC3B-II/LC3B-I, as well as for p62. Data are means \pm SEM from at least three independent experiments. ${ }^{*} p<0.05$, hypoxia versus normoxia.

\section{Hypoxia-induced responses are more evident in MMEC than in HUVEC}

Hypoxia seems to affect MMEC and HUVEC proliferative and apoptotic profiles differently. To determine whether these observations were associated with different adaptive responses to hypoxia we evaluated the hypoxic signature in both cell types. Previous reports have shown that MMEC express higher protein levels of HIF-1 $\alpha$ than do HUVEC under normoxic conditions [15]. As shown in Fig. 3a, expression of HIF-1 $\alpha$ was significantly higher in MMEC than in HUVEC under hypoxia. We then analyzed the gene expression profile associated 
Fig. 3. Hypoxic signatures in MMEC and HUVEC. (a) HIF-1 $\alpha$ protein expression after $8 \mathrm{~h}$ of hypoxia was evaluated by western blot analysis using $\beta$-actin as protein loading control. A representative blot from three independent experiments is shown. Densitometric quantification was achieved by chemiluminescence and expressed with respect to hypoxic HUVEC as control. * $\mathrm{p}<0.05$, significantly different from HU$\operatorname{VEC}(\mathrm{n}=3)$. (b) CAIX, (c) GLUT-1 and (d) MCT-4 mRNA expression was defined by real-time PCR after $24 \mathrm{~h}$ of hypoxic incubation. Data are means \pm SEM from three to four independent experiments. ${ }^{*} \mathrm{p}<0.05$, hypoxia versus normoxia.

with a hypoxic signature. We determined expression of CAIX, GLUT-1 and MCT-4, as they are all transcriptionally regulated by HIF$1 \alpha$. qRT-PCR results clearly showed that under hypoxia, CAIX, GLUT-1 and MCT-4 mRNA levels were significantly higher than in normoxic controls and more evident in MMEC than in HUVEC (Fig. 3b-d).

Among genes uniquely regulated by HIF- $1 \alpha$ at transcriptional level, BNIP3 is involved in a program exploited by several cell types to survive hypoxic insult [21]. Like HIF-1 $\alpha$, BNIP3 is highly expressed in MMEC under normoxic conditions [22]. As shown in Fig. 4a, BNIP3 was expressed more in MMEC than in HUVEC at mRNA and protein levels. To further analyze this observation, we performed kinetic experiments that showed an evident difference in BNIP3 expression profile in the two cell types (Fig. 4b). As expected, mRNA levels of BNIP3 were always higher under hypoxic conditions in both cell types. In HUVEC, exposure to hypoxia caused a modest increase in BNIP3 expression, which was enhanced at $8 \mathrm{~h}$ and then declined at $24 \mathrm{~h}$ and $48 \mathrm{~h}$. In contrast, in MMEC we observed an initial sharp increase in BNIP3 mRNA expression at $8 \mathrm{~h}$ which was further increased at $24 \mathrm{~h}$ and $48 \mathrm{~h}$. These results clearly indicate that MMEC tend to adapt to hypoxia more efficiently than HUVEC and that BNIP3 expression may play a role in cell survival.
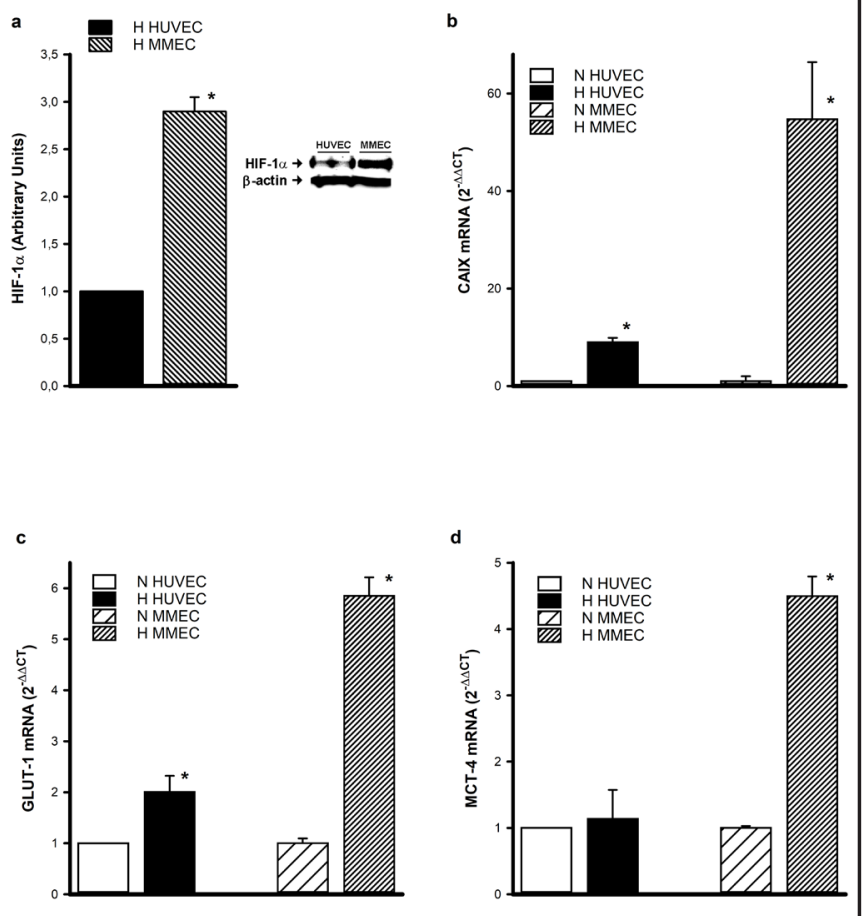

Fig. 4. BNIP3 expression in MMEC and HUVEC under hypoxia. (a) BNIP3 mRNA and protein expression were defined by real-time PCR and Western blot in MMEC and HUVEC and compared at zero time. ${ }^{*} \mathrm{p}<0.05$, significantly different from HUVEC ( $\mathrm{n}=3)$. (b) Kinetics of BNIP3 mRNA expression, as defined by real-time PCR. * $\mathrm{p}<0.05$, significantly different from normoxia.

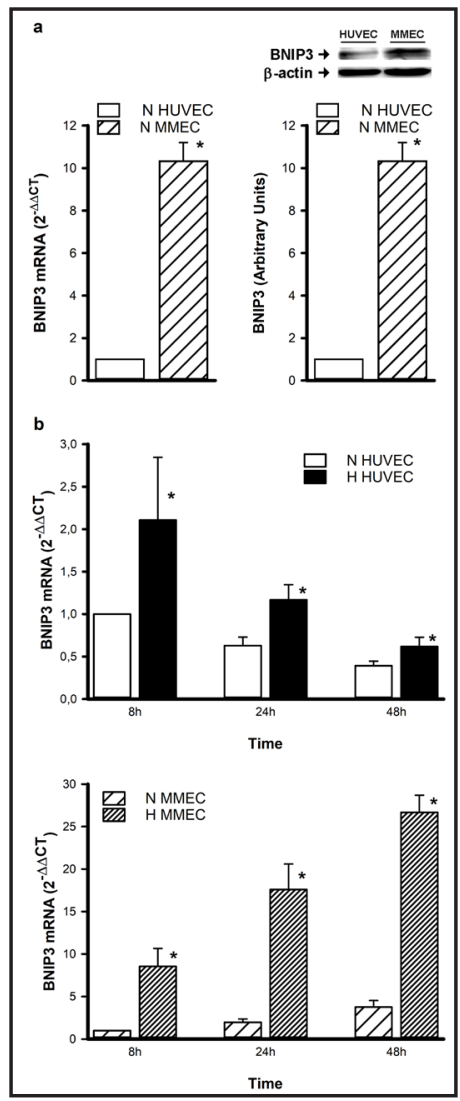


Inhibition of BNIP3 reduces HUVEC survival under hypoxia

Previous reports established a role of BNIP3 in adaptation to hypoxia by several cell types [21]. It has also been reported that ablation of BNIP3 in cells where it is overexpressed (e.g. MMEC) promoted apoptosis [22]. To better establish the role of BNIP3 in EC survival under hypoxic conditions, we evaluated proliferation and apoptosis/autophagy in HUVEC in which BNIP3 was inhibited by siRNA technology. As shown in Fig. 5a, inhibition of BNIP3 resulted in a significant reduction of BNIP3 expression at mRNA (more than 90\%) and protein levels, under normoxic and hypoxic conditions. Inhibition was associated with a reduction in cell proliferation (Fig. 5b) and enhancement of apoptosis (Fig. 5c). In contrast with the results obtained in hypoxic MMEC, where BNIP3 was overexpressed, BNIP3 inhibition in hypoxic HUVEC resulted in a reduction in the autophagic process. Indeed, the LC3B-II/LC3B-I ratio was significantly lower in hypoxic HUVEC, where BNIP3 was silenced, than in hypoxic controls (Fig. 5d). Again our results indicate a crucial role of BNIP3 not only in the survival of pathological and highly proliferative EC (i.e. MMEC) but also of normal quiescent EC (i.e. HUVEC) in a hypoxic microenvironment.

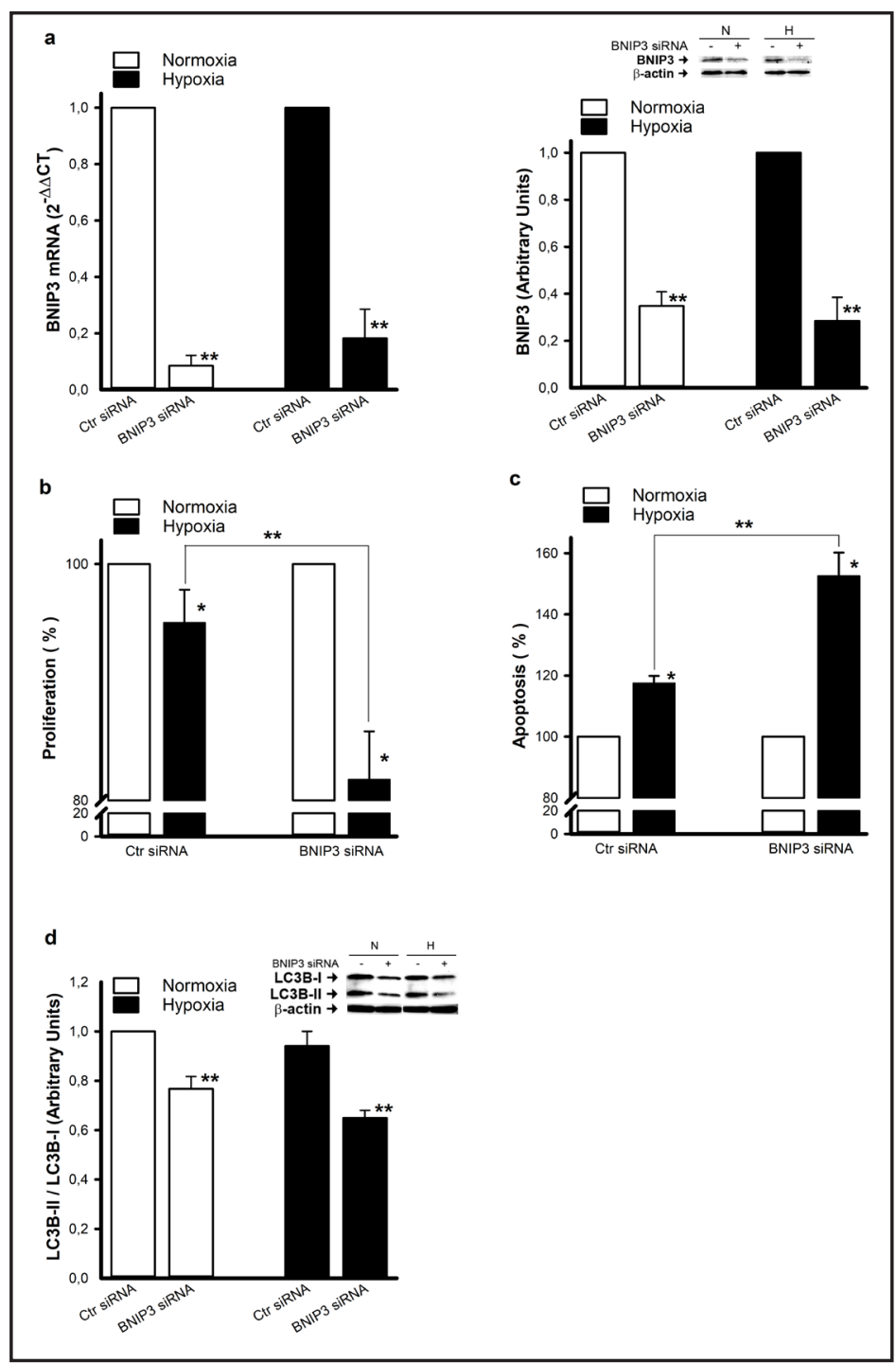

Fig. 5. Inhibition of BNIP3 by siRNA in HUVEC under hypoxia. HUVEC transfected with scrambled (Ctr siRNA) or BNIP3 siRNA were exposed to hypoxia for $48 \mathrm{~h}$. (a) BNIP3 mRNA and protein expression were determined by real-time PCR and western blot analysis. A representative blot from three independent experiments is shown. Densitometric quantification was performed by chemiluminescence. Data are presented as BNIP3 siRNA versus the corresponding Ctr siRNA. ** $\mathrm{p}<0.05$, statistically significant difference between BNIP3 siRNA and control siRNA (Ctr siRNA). (b) Cell proliferation and (c) apoptosis were expressed as percentages with respect to normoxic controls. ${ }^{*} \mathrm{p}<0.05$, significantly different from normoxia. ${ }^{* *} \mathrm{p}<0.05$, statistically significant difference between BNIP3 siRNA and control siRNA (Ctr siRNA). (d) LC3B-I and LC3B-II protein expression was evaluated by western blot analysis and a representative blot from three independent experiments is shown. Quantification data is reported as LC3B-II/LC3B-I ratio in relation to normoxic Ctr siRNA. ${ }^{* *} \mathrm{p}<0.05$, statistically significant difference between BNIP3 siRNA and control siRNA (Ctr siRNA). 


\section{Discussion}

Several reports have indicated that EC are particularly resistant to hypoxic stress. Compared to other primary cell lines, including neurons and cardiomyocytes, EC only die after prolonged exposure to hypoxia [10]. Previous studies show that EC from tumor vessels are functionally different from quiescent EC, in line with the increased angiogenesis involved in tumor progression $[23,24]$. We sought to compare the adaptive responses to hypoxia of EC from healthy quiescent vessels (HUVEC) and from tumor vessels (MMEC). This is the first report that MMEC are more resistant than HUVEC to hypoxic stress in terms of cell viability, being more prone to autophagy and less predisposed to apoptosis. The fact that MMEC were less prone to apoptosis was clarified by previous studies, which, however, were conducted under normoxic conditions [22]. In our study, we determined that HUVEC were less resistant than MMEC to cell death due to prolonged exposure to hypoxia. Indeed, short exposure to hypoxia failed to induce cell death in either cell type. This is consistent with previous observations showing that HUVEC are resistant to hypoxia-induced cell death after $24 \mathrm{~h}$ of exposure [10]. However, while HUVEC were less viable after $48 \mathrm{~h}$ of hypoxic treatment, MMEC continued to resist. Compared with HUVEC, MMEC expressed a higher level of livin and cdc25A and a lower level of p21. This is in line with previous reports indicating that downregulation of cdc25 and upregulation of p21 expression in EC correlates with cell cycle arrest $[25,26]$. With regard to livin, an inhibitor of apoptosis proteins, our observations show that its expression is positively correlated with cell survival [27]. Our results are also in agreement with previous reports indicating that hypoxia-induced death of HUVEC could be attributed to apoptosis [10]. However, the latter authors did not find any apparent correlation with alterations in Bax and Bcl-xl proteins. In our hands, such alterations were only relatively significant after $48 \mathrm{~h}$ of hypoxia. More interestingly, in hypoxic MMEC, Bax/ Bcl-xl expression was significantly reduced, in line with the hypothesis that MMEC are more resistant to hypoxia-induced cell death. It is important to underline the significant reduction in Beclin-1 expression and in the LC3B-II/LC3B-I ratio in hypoxic HUVEC. Beclin-1 is a major agent and initiator of autophagy [7] and when autophagy is activated, cytoplasmic LC3B-I protein is cleaved, lipidated and inserted into autophagosome membranes as LC3II [28]. Thus an increase in the amount of the smaller molecular weight LC3-II protein and an increase in the LC3-II/LC3-I ratio are a hallmark of autophagy and correlated with an increased number of autophagosomes. Autophagy is also associated with p62 degradation [20] and indeed here we found that hypoxic MMEC expressed lower p62 levels. As previously shown, autophagy may be considered a pro-survival adaptive response in several cell types $[8,21,29]$. This may further explain why HUVEC are less resistant to hypoxia-induced cell death than MMEC, which in comparison appeared to be more prone to autophagy.

Previous reports clearly illustrate how cells adapt to hypoxia by expression of genes closely regulated by HIF- $1 \alpha$, including CAIX, GLUT-1, MCT- 4 and BNIP3, in order to survive in a hostile microenvironment [30-33]. The fact that HUVEC tended to accumulate less HIF- $1 \alpha$ than MMEC, and that MMEC expressed higher mRNA levels of CAIX, GLUT-1, MCT-4 and BNIP3 than HUVEC, supports the hypothesis that MMEC show a better metabolic and autophagic adaptive response to hypoxic stress. Indeed, BNIP3 has been described as a key molecule induced by hypoxia and involved in the autophagic switch enabling cells to survive and to avoid apoptosis [21]. Our results fully agree with previous reports demonstrating that hypoxia-induced autophagy is a survival process and is linked to the expression of BNIP3 and BNIP3like (BNIP3L) [7]. The same authors report that ectopic expression of BNIP3 and BNIP3L triggers autophagy under normoxic conditions. It should be underlined that MMEC overexpress BNIP3 even under normoxia [22] and our results clearly define its overexpression in MMEC under hypoxic conditions. The proposed protective role of BNIP3 in EC exposed to hypoxia is further corroborated by the fact that when BNIP3 was silenced in HUVEC, we observed lower viability and increased apoptosis. This is in line with a previous study showing that increased apoptosis occurs when BNIP3 is inhibited in MMEC [22]. In 


\section{Cellular Physiology Cell Physiol Biochem 2018;46:203-212 \\ \begin{tabular}{l|l|l} 
DOI: 10.1159/000488423 & and Biochemistry & $\begin{array}{l}\text { O } 2018 \text { The Author(s). Published by S. Karger AG, Basel } \\
\text { www.karger.com/cpb }\end{array}$
\end{tabular}}

Filippi et al.: Endothelial Cell Survival Under Hypoxia

conclusion, our results suggest that understanding the mechanisms by which different EC adapt to hypoxia may have important therapeutic implications.

\section{Acknowledgements}

Contract grant sponsor: Istituto Toscano Tumori (ITT), Ministero Istruzione, Università e Ricerca (MIUR)

\section{Disclosure Statement}

The authors declare no Disclosure Statement regarding the publication of this paper.

\section{References}

1 Semenza GL: Hypoxia-inducible factors in physiology and medicine. Cell 2012;148:399-408.

2 Semenza GL: Regulation of oxygen homeostasis by hypoxia-inducible factor 1. Physiology (Bethesda ) 2009;24:97-106.

3 Nizet V, Johnson RS: Interdependence of hypoxic and innate immune responses. Nat Rev Immunol 2009;9:609-617.

4 Park SK, Dadak AM, Haase VH, Fontana L, Giaccia AJ, Johnson RS: Hypoxia-induced gene expression occurs solely through the action of hypoxia-inducible factor 1alpha (HIF-1alpha): role of cytoplasmic trapping of HIF-2alpha. Mol Cell Biol 2003;23:4959-4971.

5 Scortegagna M, Cataisson C, Martin RJ, Hicklin DJ, Schreiber RD, Yuspa SH, Arbeit JM: HIF-1alpha regulates epithelial inflammation by cell autonomous NFkappaB activation and paracrine stromal remodeling. Blood 2008;111:3343-3354.

-6 Pugh CW, Ratcliffe PJ: Regulation of angiogenesis by hypoxia: role of the HIF system. Nat Med 2003;9:677684.

7 Mazure NM, Pouyssegur J: Atypical BH3-domains of BNIP3 and BNIP3L lead to autophagy in hypoxia. Autophagy 2009;5.

-8 Gozuacik D, Kimchi A: Autophagy as a cell death and tumor suppressor mechanism. Oncogene 2004;23:2891-2906.

-9 Lum JJ, Bauer DE, Kong M, Harris MH, Li C, Lindsten T, Thompson CB: Growth factor regulation of autophagy and cell survival in the absence of apoptosis. Cell 2005;120:237-248.

10 Stempien-Otero A, Karsan A, Cornejo CJ, Xiang H, Eunson T, Morrison RS, Kay M, Winn R, Harlan J: Mechanisms of hypoxia-induced endothelial cell death. Role of p53 in apoptosis. J Biol Chem 1999;274:8039-8045.

11 Jurasz P, Yurkova N, Kirshenbaum L, Stewart DJ: VEGF masks BNIP3-mediated apoptosis of hypoxic endothelial cells. Angiogenesis 2011;14:199-207.

12 Ausprunk DH, Falterman K, Folkman J: The sequence of events in the regression of corneal capillaries. Lab Invest 1978;38:284-294.

$>13$ Semenza GL: Angiogenesis in ischemic and neoplastic disorders. Annu Rev Med 2003;54:17-28.

-14 Vacca A, Ria R, Semeraro F, Merchionne F, Coluccia M, Boccarelli A, Scavelli C, Nico B, Gernone A, Battelli F, Tabilio A, Guidolin D, Petrucci MT, Ribatti D, Dammacco F: Endothelial cells in the bone marrow of patients with multiple myeloma. Blood 2003;102:3340-3348.

15 Ria R, Catacchio I, Berardi S, De Luisi A, Caivano A, Piccoli C, Ruggieri V, Frassanito MA, Ribatti D, Nico B, Annese T, Ruggieri S, Guarini A, Minoia C, Ditonno P, Angelucci E, Derudas D, Moschetta M, Dammacco F, Vacca A: HIF-1 alpha of Bone Marrow Endothelial Cells Implies Relapse and Drug Resistance in Patients with Multiple Myeloma and May Act as a Therapeutic Target. Clin Cancer Res 2014;20:847-858. 


\section{Cellular Physiology Cell Physiol Biochem 2018;46:203-212

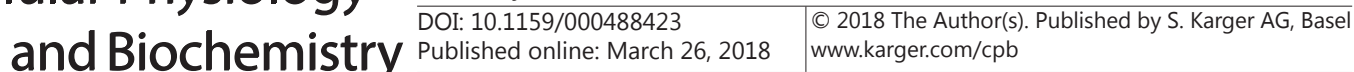

Filippi et al.: Endothelial Cell Survival Under Hypoxia

16 Colla S, Tagliaferri S, Morandi F, Lunghi P, Donofrio G, Martorana D, Mancini C, Lazzaretti M, Mazzera L, Ravanetti L, Bonomini S, Ferrari L, Miranda C, Ladetto M, Neri TM, Neri A, Greco A, Mangoni M, Bonati A, Rizzoli V, Giuliani N: The new tumor-suppressor gene inhibitor of growth family member 4 (ING4) regulates the production of proangiogenic molecules by myeloma cells and suppresses hypoxia-inducible factor-1 alpha (HIF-1alpha) activity: involvement in myeloma-induced angiogenesis. Blood 2007;110:44644475.

-17 Filippi I, Morena E, Aldinucci C, Carraro F, Sozzani S, Naldini A: Short-term hypoxia enhances the migratory capability of dendritic cell through HIF-1alpha and PI3K/Akt pathway. J Cell Physiol 2014;229:2067-2076.

18 Naldini A, Filippi I, Cini E, Rodriquez M, Carraro F, Taddei M: Downregulation of Hypoxia-related Responses by Novel Antitumor Histone Deacetylase Inhibitors in MDAMB231 Breast Cancer Cells. Anticancer Agents Med Chem 2012;12:407-413.

19 Livak KJ, Marmaro J, Todd JA: Towards fully automated genome-wide polymorphism screening. Nat Genet 1995;9:341-342.

20 Frassanito MA, De Veirman K, Desantis V, Di Marzo L, Vergara D, Ruggieri S, Annese T, Nico B, Menu E, Catacchio I, Ria R, Racanelli V, Maffia M, Angelucci E, Derudas D, Fumarulo R, Dammacco F, Ribatti D, Vanderkerken K, Vacca A: Halting pro-survival autophagy by TGFbeta inhibition in bone marrow fibroblasts overcomes bortezomib resistance in multiple myeloma patients. Leukemia 2016;30:640-648.

-21 Bellot G, Garcia-Medina R, Gounon P, Chiche J, Roux D, Pouyssegur J, Mazure NM: Hypoxia-induced autophagy is mediated through hypoxia-inducible factor induction of BNIP3 and BNIP3L via their BH3 domains. Mol Cell Biol 2009;29:2570-2581.

22 Ria R, Todoerti K, Berardi S, Coluccia AM, De Luisi A, Mattioli M, Ronchetti D, Morabito F, Guarini A, Petrucci MT, Dammacco F, Ribatti D, Neri A, Vacca A: Gene expression profiling of bone marrow endothelial cells in patients with multiple myeloma. Clin Cancer Res 2009;15:5369-5378.

-23 Holmgren L, O’Reilly MS, Folkman J: Dormancy of micrometastases: balanced proliferation and apoptosis in the presence of angiogenesis suppression. Nat Med 1995;1:149-153.

24 Folkman J: Role of angiogenesis in tumor growth and metastasis. Semin Oncol 2002;29:15-18.

25 Porcu E, Viola G, Bortolozzi R, Persano L, Mitola S, Ronca R, Presta M, Romagnoli R, Baraldi PG, Basso G: TR-644 a novel potent tubulin binding agent induces impairment of endothelial cells function and inhibits angiogenesis. Angiogenesis 2013;16:647-662.

26 Singh RP, Dhanalakshmi S, Agarwal C, Agarwal R: Silibinin strongly inhibits growth and survival of human endothelial cells via cell cycle arrest and downregulation of survivin, Akt and NF-kappaB: implications for angioprevention and antiangiogenic therapy. Oncogene 2005;24:1188-1202.

27 Wong JC, Fiscus RR: Resveratrol at anti-angiogenesis/anticancer concentrations suppresses protein kinase G signaling and decreases IAPs expression in HUVECs. Anticancer Res 2015;35:273-281.

28 Tanida I, Ueno T, Kominami E: LC3 conjugation system in mammalian autophagy. Int J Biochem Cell Biol 2004;36:2503-2518.

29 Wang HJ, Zhang D, Tan YZ, Li T: Autophagy in endothelial progenitor cells is cytoprotective in hypoxic conditions. Am J Physiol Cell Physiol 2013;304:C617-626.

-30 Chiche J, Ilc K, Laferriere J, Trottier E, Dayan F, Mazure NM, Brahimi-Horn MC, Pouyssegur J: Hypoxiainducible carbonic anhydrase IX and XII promote tumor cell growth by counteracting acidosis through the regulation of the intracellular pH. Cancer Res 2009;69:358-368.

-31 Robey IF, Stephen RM, Brown KS, Baggett BK, Gatenby RA, Gillies RJ: Regulation of the Warburg effect in early-passage breast cancer cells. Neoplasia 2008;10:745-756.

-32 de Heredia FP, Wood IS, Trayhurn P: Hypoxia stimulates lactate release and modulates monocarboxylate transporter (MCT1, MCT2, and MCT4) expression in human adipocytes. Pflug Arch Eur J Phy 2010;459:509518.

33 Mellor HR, Harris AL: The role of the hypoxia-inducible BH3-only proteins BNIP3 and BNIP3L in cancer. Cancer Metastasis Rev 2007;26:553-566. 